
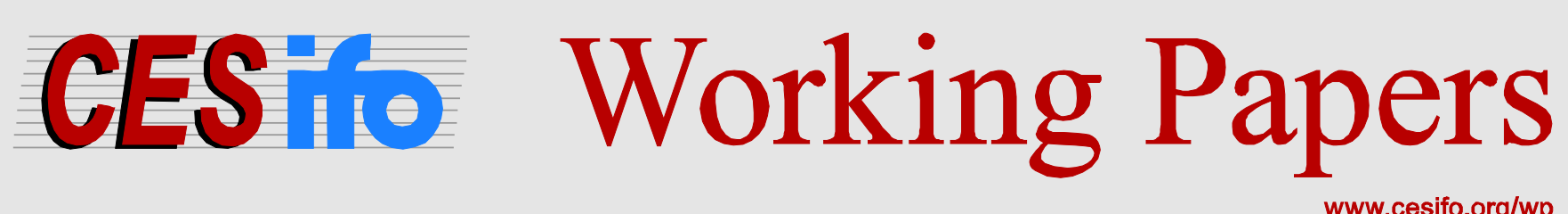

www.cesifo.org/wp

\title{
Forecasting Exchange Rates: An Investor Perspective
}

\author{
Michael Melvin \\ John Prins \\ Duncan Shand
}

\author{
CESIFO WORKING PAPER NO. 4238 \\ CATEGORY 7: MONETARY POLICY AND INTERNATIONAL FinANCE \\ MAY 2013
}

An electronic version of the paper may be downloaded

- from the SSRN website:

- from the RePEc website:

- from the CESifo website:

WWW.SSRN.com

www.RePEc.org

www.CESifo-group.org/wp

\section{CESifo}




\title{
Forecasting Exchange Rates: An Investor Perspective
}

\begin{abstract}
The popular scholarly exercise of evaluating exchange rate forecasting models relative to a random walk was stimulated by the well-cited Meese and Rogoff (1983) paper. Practitioners who construct quantitative models for trading exchange rates approach forecasting from a different perspective. Rather than focus on forecast errors for bilateral exchange rates, as in the Meese-Rogoff case, we present what is required for constructing a successful trading model. To provide more perspective, a particular approach to quantitative modeling is presented that incorporates return forecasts, a risk model, and a transaction cost constraint in an optimization framework. Since beating a random walk is not a useful evaluation metric for currency investing, we discuss the use of benchmarks and conclude that performance evaluation in currencies is much more problematic than in equity markets due to the lack of a passive investment strategy and the multitude of alternative formulations of well-known currency style factors. We then provide analytical tools that can be useful in evaluating currency manager skill in terms of portfolio tilts and timing. Finally, we examine how conditioning information can be employed to enhance timing skill in trading generic styles like the carry trade. Such information can be valuable in reducing the duration and magnitude of portfolio drawdowns.
\end{abstract}

JEL-Code: C520, C530, C580, F310, F370, G150, G170.

Keywords: exchange rate forecasting, forecast evaluation, conditioners, quantitative models, benchmarks.

Michael Melvin

BlackRock San Francisco / USA

michael.melvin@blackrock.com

John Prins

BlackRock San Francisco / USA john.prins@blackrock.com
Duncan Shand

BlackRock London / United Kingdom duncan.shand@blackrock.com

Forthcoming in Elliott and Timmermann Handbook of Economic Forecasting; Vol 2; Elsevier. 


\section{Introduction}

Exchange rate forecasting consumes a vast amount of space in the scholarly literature of international finance. Summaries of this large literature have been provided from time to time by several authors ${ }^{1}$ but the focus has generally been on finding models that can forecast the future spot exchange rate better than a random walk. The well-cited paper by Meese and Rogoff (1983) spawned a leap in research attention as scholars attempted to take up the challenge of developing new models to beat a random walk for exchange rates. It is not clear that we have learned much since the 1980s other than it is still quite challenging to construct a model that is capable of systematically outperforming a random walk in predicting future spot exchange rates. This academic focus on predicting bilateral exchange rates is understandable and certainly a subject worthy of scholarly attention, however the exercise undertaken by scholars is pursuing answers to questions that are not necessary for successful investing in currency markets. This chapter aims to lay out key issues of exchange rate forecasting from a quantitative practitioner's perspective. By the end of the chapter, the reader should have answers to the following questions:

\section{Why don't we need accurate forecasts of future spot exchange rates to construct} currency portfolios that yield attractive returns?

Section 2 addresses the irrelevance of the Meese-Rogoff exchange rate disconnect puzzle for currency investors. Of course, Meese and Rogoff were focused on testing popular exchange rate models from an academic perspective and not creating investment portfolios. One way of viewing the difference is in terms of different loss functions. The academic exercise uses a measure like mean square forecasting error, while the active currency investor focuses on a measure like a Sharpe ratio or risk-adjusted returns. We will give a clear example of the difference that results from the two perspectives. ${ }^{2}$

\section{How does one go about constructing an actively managed currency portfolio?} Section 3 provides a high-level overview of the elements of building actively-managed quantitative currency portfolios as a currency hedge fund manager might use. While currency return forecasts are key, one needs more than just return forecasts to put together a successful long-short model.

\section{How should currency portfolio managers be evaluated?} A simple answer is whether they generate attractive risk-adjusted returns or not. But is there such a concept as "beta" in currency investing, as exists in equity investing? In other words, is there a passive investment style benchmark against which one can judge

\footnotetext{
${ }^{1}$ Papers giving a good overview of this vast literature include Frankel and Rose (1995), Taylor (1995); Sarno and Taylor (2002); Cheung, Chinn, and Pascual (2005); Engel, Mark, and West (2007); Della Corte, Sarno, and Tsiakas (2009); Williamson (2009); and Evans (2011)

${ }^{2}$ Other authors have considered alternatives to mean square forecast error in evaluating forecasts in other financial settings. Foreign exchange examples include Elliott and Ito (1999) and Satchell and Timmermann (1995).
} 
performance in currency investing? Section 4 looks into this question and finds that identifying useful benchmarks for active currency investing is problematic.

4. Lacking good benchmarks for assessing currency portfolio performance, are there other analytical tools that can be employed to help evaluate portfolio managers?

Section 5 describes how one can break down portfolio returns to evaluate a manager's skill in timing return-generating factors. Portfolio returns are decomposed into tilt and timing components. The "tilt" in a portfolio refers to holding constant exposures to assets over time, and is a kind of passive investing. The "timing" component of portfolio returns is the difference between total returns and the tilt returns. We can see that different generic currency investing styles offer different tilt versus timing returns.

5. Can one enhance returns by the use of conditioning information to help time exposures to return-generating factors?

Following on from the timing discussion of Section 5, Section 6 creates a specific example of the use of conditioning information to enhance returns from the carry trade. A carry trade involves buying (or being long) high interest rate currencies, while selling (or being short) low interest rate currencies. By dialing down risk in times of financial market stress, one can realize substantially higher returns from investing in the carry trade.

The chapter concludes with a summary in Section 7. 


\section{Successful investing does not require beating a random walk}

The inability of macroeconomic models to generate point forecasts of bilateral exchange rates that are more accurate than forecasts based on the assumption of a random walk, particularly at horizons shorter than one year, is known as the "exchange rate disconnect puzzle' (Obstfeld and Rogoff 2001). Since it was first established by Meese and Rogoff (1983), this puzzle has mostly resisted a quarter century of empirical work attempting to overturn it, and remains one of the best-known challenges in international finance. Despite its prominence in academic work, however, this challenge is of little relevance to investors. The investor's goal is not to generate accurate forecasts of the future levels of exchange rates, but simply to generate forecasts of returns to these currencies that are correctly rank-ordered in the cross-section. It is the ordering of these return forecasts relative to one another that matters, not their absolute magnitude. An investor's forecasts of returns might be substantially worse than those of a random walk, but as long as they are more or less correctly ordered relative to one another, one can still consistently make money. In short, successful investing does not require beating a random walk.

To illustrate the difference between the approaches of the typical academic and practitioner, consider the following simple example. Suppose the investor has three currencies in his tradeable universe: dollar, euro and yen. EURUSD today is trading at 1.50 and USDJPY is trading at 100 . He forecasts the Yen to depreciate by $10 \%$ (leaving USDJPY at 111) and the Euro to appreciate by $10 \%$ (leaving EURUSD at 1.65). He therefore takes a long position of $+50 \%$ Euro and an offsetting short position of $-50 \%$ Yen in his portfolio, while remaining neutral on the dollar ${ }^{3}$. Subsequently, EURUSD ends the period at 1.4850 (a depreciation of 1\%) and USDJPY ends the period at 105 (a depreciation of 5\%). The root mean squared error of the investor's forecasts ( $\operatorname{sqrt}(((111-$ $\left.\left.\left.\left.105) / 105)^{\wedge} 2+(1.65-1.4850) / 1.4850\right)\right)^{\wedge} 2\right)=12.5 \%\right)$, is much larger than the root mean squared error of a forecast based on the random walk $\left(\operatorname{sqrt}\left(((100-105) / 105)^{\wedge} 2+(1.50-\right.\right.$ $\left.1.4850) / 1.4850))^{\wedge} 2\right)=4.8 \%$ ). The investor has made two serious mistakes: the magnitude of his forecasts was totally wrong, expecting moves of $10 \%$ in either direction when only moves of $1 \%$ and $5 \%$ were realized, and he did not even predict one of the two directions of change correctly. Nonetheless, despite large errors in his forecasts in regards to both direction and magnitude, his portfolio made a $2 \%$ positive return. This is simply because his rank ordering of returns for the currencies in which he took active positions (i.e. EUR $>$ JPY) was correct.

This example demonstrates one of the advantages which the investor has over the academic. Theory often suggests which fundamental macroeconomic variables should be relevant to exchange rate determination while remaining silent on the size of the

\footnotetext{
${ }^{3}$ There are many other portfolios the investor could have formed that are consistent with the forecasts of relative returns that he generated. In practice, the level of risk the investor desires, and his determination of the optimal hedging portfolio for each position, will determine the exact composition of the portfolio. Here we choose a simple portfolio for illustrative purposes, with no hedging through the third currency (the dollar).
} 
relationship (ie the true coefficient in a regression of the exchange rate on the fundamental in question). Thus, for the researcher attempting to produce an accurate forecast of an exchange rate's future level, it is necessary to empirically estimate the relationship which existed historically between the exchange rate and the fundamental, and use these historical estimates to inform his forecasts. This entails all sorts of difficulties, including the problems of estimation error in short samples and the possibility of structural breaks. But as long as the same relationship, whatever it is, holds across currencies, the investor does not have to worry about these estimation issues. It is sufficient to rank the currencies in his investible universe according to the fundamental in question (in level or change space, whichever is more appropriate), and form his longshort portfolio accordingly ${ }^{4}$.

The second advantage of the investor is breadth. The Fundamental Law of Active Management (Grinold and Kahn, 2000) says that a portfolio of 17 currencies (i.e. 16 exchange rates), formed on the basis of forecasts with equal ex-ante skill across currencies, will have a information ratio ${ }^{5}$ four times higher than that of a portfolio consisting of only 2 currencies (i.e., a single exchange rate). Many academic studies, following Mark and Sul (2001), have also recognized the benefits of breadth and made use of panel forecasts to overcome the problems of estimating relationships in short samples, with moderate success at very long horizons. Nonetheless, in terms of evaluating the success of their forecasts, the majority of the attention has remained fixed on bilateral exchange rates, ${ }^{6}$ whereas the investor's success is measured across the realized cross-section of returns.

The rest of this section develops a real example of a fundamental we might expect to have relevance to forecasting exchange rates, and evaluates it against the academic's and investor's benchmarks, showing that while it has only very limited success in the academic context, it fares better as an investment strategy. Consider the concept of purchasing power parity, which states that the same tradeable good should sell for the same price in different currencies. For non-tradable goods, between countries with very different levels of productivity in their tradable sectors, this law certainly need not hold (Dornbusch, 1979) - think of the difference in price between a haircut in India and Switzerland. But it is a reasonable working hypothesis for countries at roughly the same

\footnotetext{
${ }^{4}$ If the investor wishes to use more than one fundamental to rank currencies, a difficulty can arise if two factors are highly correlated and have opposite signs. Then it becomes necessary to know the relative magnitudes of the two effects. To circumvent this difficulty in practice, investors simply try to make sure the fundamentals they use as the building blocks of their portfolios are fairly independent.

${ }^{5}$ The information ratio (IR) is the expected active return (the return in excess of a passive benchmark return) divided by the standard deviation of the active return. Section 5 provides some examples generating IR values, while Section 4 discusses the challenges of identifying useful benchmark portfolios for active currency investing.

${ }^{6}$ For an example of a recent paper which uses panel estimation techniques, but still evaluates forecast accuracy against each bilateral exchange rate independently, see Molodtsova and Papell (2009). For examples of recent papers which do evaluate the success of strategies in a portfolio setting, see Burnside, Eichenbaum, Kleshchelski and Rebelo (2006), Lustig and Verdelhan (2007), Ang and Chen (2010) and Lustig, Roussanov and Verdelhan (2011).
} 
level of economic development, and low barriers to trade and technological diffusion, that if a country's currency deviates significantly from purchasing power parity with its peers, we might expect it to revert. Using data on relative price levels between countries, together with current spot exchange rates, we can therefore construct forecasts for each currency at each point in time based on the hypothesis of reversion to PPP, and test our model both in an academic and a portfolio setting.

In terms of data, we proceed as follows. In its biannual World Economic Outlook reports, the International Monetary Fund publishes estimates of purchasing power parity based on sporadic surveys conducted by the International Comparison Program (ICP), a division of the World Bank. At each point in time, we take the latest estimate of purchasing power parity available at the time as our estimate of the currency's fair value. Then, the deviation of the current spot price from this fair value, in percentage terms, is our forecast of the expected change in the spot price. To be precise, if the spot price is defined in terms of units of the currency per US dollar, then a spot price higher than the fair value determined by the IMF's estimates of purchasing power parity indicates that the currency is weaker than fair value, and we therefore forecast for this currency a positive return.

We use the exchange rates of the eight developed countries which have been continuously in existence since 1980 when the IMF's PPP data first becomes available: the British Pound, the Japanese Yen, the Swiss Franc, the Canadian Dollar, the Australian Dollar, the New Zealand Dollar, the Swedish Krona and the Norwegian Krone. For the purposes of this exercise, we omit the Euro and its forebears as they have only been in existence for (mutually exclusive) parts of the sample. In each month, the value of PPP that we use is that which was published in the previous year's October WEO report. The value of spot that we use is the London $4 \mathrm{pm}$ WM fixing price ${ }^{7}$ from two days prior to the beginning of the month. The use of PPP estimated from the previous year, and spot data from the previous month, ensures that the data we use in our forecast were available at the time the forecast was made, and that the forecasts are therefore out-of-sample and the trading strategy based on it is investible. Figure 1 plots the spot exchange rate along with the PPP-implied fair value for each currency.

We contrast the results of two different approaches to evaluating the relevance of these forecasts to exchange rates: the academic approach of whether we can reject the null hypothesis that each exchange rate follows a random walk, and the practitioner's approach of whether a portfolio formed on the basis of these forecasts has a information ratio statistically significantly different from zero. For the first approach, we use four standard tests of out-of-sample predictability applied in the literature: Clark-West, ClarkMcCracken, Diebold-Mariano and Theil's U. For the second approach, we construct a long-short portfolio of the currencies in our universe, rebalanced at the beginning of each month. More details on how such portfolios are typically constructed by quantitative investors are provided in Section 4. For the purposes of evaluating the performance of the

\footnotetext{
${ }^{7}$ The London 4pm WM fixing price is a benchmark price provided by Reuters (formerly WM Company) for foreign exchange.
} 
long-short portfolio, we compare it to a benchmark portfolio with zero holdings. This is the portfolio which would be generated (also using the methodology of Section 2) by an assumption of uncovered interest rate parity, where the expected exchange rate change is equal to the interest differential so that there is no expectation of gain from currency speculation. The question of whether this is the most appropriate benchmark for a currency strategy is discussed in more detail in the next section.

The results are shown in Table 1. In the first approach, for no currency are we able to reject the null hypothesis of a random walk consistently across all four tests. In fact, we can reject the null for only one currency (CAD) in one test (Clark-McCracken). The tests across the whole panel of currencies fare slightly better, with success at rejecting the null at the $1 \%$ significance level for two tests (Clark-West and Clark-McCracken), but again the results are inconsistent across the four tests. We could interpret this as some evidence that our forecasts contain information that enables us to predict the future levels of exchange rates better than a random walk, but only for the panel. By contrast, in the second approach, the information ratio of the portfolio formed from our forecasts is 0.5 . The statistical significance of this information ratio can be evaluated by noting that the tstatistic is approximately equal to the information ratio multiplied by the square root of time in years (Grinold and Kahn, 2000). In this case this yields a t-statistic of $0.5 *$ $\operatorname{sqrt}(30)=2.7$, indicating that the information ratio is statistically significantly different from zero ${ }^{8}$. A visual inspection of cumulative returns to the portfolio (shown in Figure 2), normalized to take unit risk, also suggests that performance has been quite consistent over time.

In summary, the goal of an investor in foreign exchange markets is different to that of much of the academic literature on forecasting exchange rates. While the gold standard for academics has been to produce accurate point forecasts for the future levels of bilateral exchange rates, the investor has an easier task. One only need be concerned with generating expected returns across a cross-section of currencies which correspond well to the actual cross-section of realized relative returns. Errors in forecasts can be averaged out over a large cross-section of currencies, and the rank order of the forecasts matters more than their size. We showed an example of a fundamental that, while unable to beat a random walk for any of the individual exchange rates in our sample, generated an investing strategy which most investors would find fairly attractive. In the sections that follow, we go into more detail of the investor's approach: how to construct a portfolio, how to evaluate this portfolio's performance, and appropriate benchmarks against which to measure this performance.

\footnotetext{
${ }^{8}$ Lo (2002) outlines the conditions under which this Grinold and Kahn (2000) result holds, the most important of which is the absence of serial correlation in returns to the portfolio.
} 


\section{Constructing a Currency Portfolio}

Building a quantitatively modeled active currency portfolio involves 3 key pieces: return or alpha ${ }^{9}$ forecasts, a risk model, and a transaction cost model. ${ }^{10}$ We can summarize this with the following utility function to be maximized (over $h$ ): $h^{\prime} \alpha-\lambda h^{\prime} V h-\theta T C|\Delta h|$, where $h$ refers to the portfolio holdings or positions, $\alpha$ is the alpha or return forecast, $\lambda$ is the parameter of risk aversion, $V$ is the risk model or, typically, a covariance matrix of returns, $\theta$ is the transaction cost amortization factor, $T C$ is a transaction cost function, and $|\Delta h|$ is the change in holdings from last period to this period. A long-short hedge fund has both positive and negative holdings, so one may also include a sum-to-zero constraint so that the model is self-funding (the short positions fund the long positions). We discuss each of these elements of the utility function in turn.

- $h$ : the portfolio asset holdings are derived from the utility maximization or optimization of the portfolio subject to the return forecasts, risk constraint, and transaction cost model.

- $\quad \alpha$ : the alpha or return forecast is the key element of the whole enterprise. No matter how good the risk and transaction cost models, without good forecasts of returns, no quantitative model can survive. However, what really matters is not the forecast of actual returns, but the relative ranking of returns across the assets in the fund in order to identify favored long positions versus shorts. So $\alpha$ is aimed at more of an ordinal ranking than a true expectation.

- $\lambda$ : the risk aversion parameter is used to scale risk up or down to achieve a target level of risk. In order to raise (lower) the risk level of the portfolio, we lower (raise) $\lambda$.

- $\quad V$ : is typically a covariance matrix estimated from historical returns. Managers may apply some Bayesian shrinkage based upon prior information regarding elements of the matrix. For instance, one may want to force regional blocks to always exist so that one creates baskets of currencies for hedging that focus on Asia, Europe, and the Americas to ensure that the returns of currencies in each block are correlated to a sufficient degree. Alternatively, some managers may blend historical measures of correlation with forward-looking information as contained in the implied volatility from option prices. ${ }^{11}$

- $\theta$ : the transaction cost amortization factor controls how much the cost model intimidates trading. If one wants to penalize the optimization via transaction costs more, then $\theta$ is raised. If $\theta$ is set to zero, then the model moves to the no-cost

\footnotetext{
${ }^{9}$ Investors often refer to idiosyncratic returns of an asset as "alpha." This term comes from equity investing where "beta" is the return that is correlated with the overall market and alpha is the return unique to an asset.

${ }^{10}$ This is not intended to be more than a sketch of model construction techniques. For greater detail on active portfolio model building see Grinold and Kahn (2000).

${ }^{11}$ There are many ways to construct $V$ and there is a fairly large literature associated with the topic. Some examples of papers in this area that show the variety of approaches include Jorion (1985), Shanken (1987), Bollerslev, Engle, and Wooldridge (1988), Konno and Yamazaki (1991), Kroner and Ng (1998), Stevens (1988), Ledoit and Wolf (2004), and Christensen, Kinnebrock, and Podolskij (2010),
} 
optimal holdings every day. Typically, this is too much trading and the costs seriously erode the realized returns. The higher the $\theta$ for given cost forecasts, the slower we will trade to reach our desired positions. This means that the model will typically have some backlog as the difference between the zero cost optimal holdings and the transaction cost intimidated holdings, and this backlog existence is optimal. The choice of $\theta$ will also depend upon the speed of the factors driving the model holdings. For a slow model, a relatively high value may be optimal as one would not need to trade quickly into new positions as the return forecasts are persistent.

- $T C$ : the transaction cost function generates estimates of the cost of trading. We can think of the trade costs as being of two types: a) fixed costs, as in a bid-ask spread that one must pay; and b) variable costs, as in the market impact of our trades. The latter arises as our trades may affect the market price. If we are a small fund, then we will trade small size in all our currencies and market impact is not a concern. However, if we are a large fund then we will find that the market impact of our trades may be significant at times and will be increasing in trade size. Costs differ across currencies, so that we will not have to worry too much about trading euro (EUR) versus the U.S. dollar (USD), the most liquid market. However, if we trade a lessliquid currency like the New Zealand dollar (NZD) or Norwegian kroner (NOK) against the dollar, we will have to be much more careful if we are trading in size. Table 2 provides information on different transaction costs associated with different currencies. These are representative spreads a customer would face if calling a bank and requesting a two-way quote. One can see that costs vary inversely with liquidity of the currency pair. Trading U.S. dollars against euros at the commonly quoted units of dollars per euro (EURUSD), has the lowest cost as the most liquid currency pair in the market. Trading U.S. dollars against New Zealand dollars at the exchange rate quoted in USD per NZD (NZDUSD), being the least liquid currency pair in the table, has the highest cost. ${ }^{12}$

As stated earlier, the most important input into the optimization is the alpha or return forecast. In the previous section we discussed the importance of getting the ordering of currencies correct, from the most likely to appreciate to the most likely to depreciate. If we are unable to forecast this with skill over time, we will not succeed no matter how good the risk or transaction cost models are. If we have skill, then we will generate alpha over time. There remains an issue of how an active currency manager should be judged. Are there benchmarks against which performance can be measured as in equity investing? The next section takes up this controversial issue.

\section{Benchmarks for Currency Investors}

Academic forecasting exercises focus on metrics like mean square error when evaluating alternative forecasts. In the academic literature on forecasting exchange rates, the most

\footnotetext{
12 There is a limited literature on currency transaction costs. A representative sample of papers includes Glassman (1987); Bessembinder (1994); Bollerslev and Melvin (1994); Hartmann (1999); Naranjo and Nimalendran (2000); Melvin and Taylor (2009); and Ramadorai (2007).
} 
popular metric is comparing the mean square error of a particular forecast of bilateral exchange rates against that of a random walk. On the other hand, investors measure forecast success in terms of model performance in delivering risk-adjusted returns. There are two broad categories of investing: passive and active. A passive investment strategy seeks to achieve the same return as some benchmark, like the S\&P 500 index of U.S. equities for passive equity investing. The passive investor holds a portfolio of assets that will replicate the benchmark return. Active investors seek to outperform a benchmark return. So active investing in U.S. equities should seek to deliver returns in excess of a benchmark like the S\&P 500. If the active investment strategy cannot outperform the benchmark, then the investor would be better served by just choosing a lower-cost passive strategy and not trying to "beat the market." Foreign exchange markets are different from other asset classes in some important respects. From an investor's perspective, one important difference is the lack of a well-defined benchmark to be used in assessing investment manager performance. This leads to questions like the following: How should an active currency manager be evaluated? From the broader perspective, evaluating the currency forecasts of an active currency manager is more complicated than in other asset classes due to the lack of an accepted metric for "passive" performance. ${ }^{13}$

Unlike the equity market, where popular notions of "the market" exist, there is nothing like that in currencies. One can buy the S\&P 500 index and feel reasonably comfortable that you have a broad exposure to the U.S. equity market. In the foreign exchange market, one does not "buy and hold." Since every trade in the foreign exchange market involves buying one currency while selling another, an investor is naturally long and short across the chosen currencies. So how may one think about a passive strategy in currencies? First, there is no such thing as a purely passive strategy. All the various indices that have been suggested for currency investors involve some degree of active management in that they must be rebalanced over time as market conditions change. One may conclude that there really is no passive strategy for currency investors. As a result, trade execution and strategy are extremely important.

If we rule out the concept of passive investing in the currency market, can we still identify useful benchmarks for performance evaluation? The suggested benchmarks have all been indices representing known investment strategies in the currency market: carry, trend (sometimes called momentum), and value (often some version of purchasing power parity). Rather than passive strategies, one may think in terms of common risk factors that currency investors are exposed to. In this spirit, there have been suggestions that active managers should beat these common factors in order to add value. However, there are many ways that such strategies are employed by investors and the indices on offer reflect interesting differences. So the common factors are really not exactly "common." For an example, we analyze a representative sample of indices.

\footnotetext{
${ }^{13}$ Papers that address the issue of benchmarks for active currency management include Leqeux and Acar (1998); Paape (2003); Pojarliev and Levich (2008, 2010, 2011) and Melvin and Shand (2011).
} 
Figure 3 displays cumulative returns from three different trend strategies as offered by indices created by the Centre for International Banking Economics and Finance (known as the AFX Currency index), Credit Suisse (CS), and Deutsche Bank (DB). The AFX and DB samples begin in June 1989, while the CS sample begins in June 1999. A cursory look at the figure suggests that there is no such thing as a single concept of "trend." Each firm has a different approach to modeling exchange rate momentum.

- DB calculates 12-month returns and then once-a-month ranks the G10 currencies, going long the top 3 while shorting the bottom 3 .

- AFX uses three moving averages of 32, 61, and 117 days and if the current spot rate exceeds (is less than) a moving average value a long (short) position is established. The benchmark return is the average of the returns from the three rules.

- CS defines "trend" as a 12-month exponentially-weighted moving average of total returns (including carry or the interest rate) and then takes long (short) positions in currencies whose total returns are above (below) the trend. So this trend concept includes an element of carry.

The cumulative performance of the three different strategies in Figure 4.1 are quite different at times. One can observe periods when one index is rising while others are flat or falling. The lesson is that even a simple concept like "trend" can be employed many different ways which yield differential performance so that it is an oversimplification to claim that there are clear benchmarks for applying in currency markets. This is reflected in academic studies of technical analysis in currency markets where survey data indicate a wide variety of trading rules are employed in trend-following strategies as reported in the survey by Menkhoff and Taylor (2007). ${ }^{14}$

To further investigate the extent to which alternative reasonable measures of "benchmark factors" may differ, we examine correlations across a set of alternative indices as provided by Deutsche Bank (DB), Credit Suisse (CS), and Citi. For Trend, we also include the AFX index that was studied by Pojarliev and Levich (2008). Table 3 displays the estimated correlations. Trend factor index correlations range from 0.20 for AFX/DB to 0.76 for CS/DB. Carry factor index correlations range from 0.46 for Citi/CS to 0.81 for Citi/DB. Finally, PPP factor index correlations range from 0.39 for CS/DB to 0.45 for Citi/DB or Citi/CS. Clearly the notion of a "generic" strategy in currency investing does not result in alternative indices of the generic factors looking much alike. This is unlike the case of equity markets where the S\&P 500 and the Dow Jones Industrial average have a correlation of 0.99 over the period from March 1980 to March 2010. In the case of equities, it is entirely reasonable to talk about the "market" and then benchmark returns against such a concept. In currency markets, the situation is much different.

\footnotetext{
${ }^{14}$ There is a fairly large literature on so-called technical trading rules for trading currencies, which include trend-following strategies. A sample of papers includes James (2003); Okunev and White (2003); Neely and Weller (2009); De Zwart, G., Markwat, T., Swinkels, L., and van Dijk (2009); and Menkhoff, Sarno, Schmeling, and Schrimpf (forthcoming).
} 
Melvin and Shand (2011) analyze a data set of currency hedge fund managers to examine if the generic investment styles can explain their performance. In other words, were they just trading the well-known strategies of momentum, trend, and carry, in which case some might assert that this was just earning "beta" rather than "alpha?" The empirical results indicate that returns associated with those currency investors are often generated quite independently from the generic style factors. This seems to be particularly true of the most successful managers. An analysis of timing ability reveals that some managers appear to have superior ability to time the factors. Such skill is what investors should willingly pay for. An additional skill involves risk controls and the analysis indicates that many managers have ability in avoiding worst-case drawdowns that are associated with a mechanical implementation of the generic factors. Loss avoidance is appreciated more now, in the aftermath of the crisis, than pre-crisis and this is a skill that is rewarded in the market. All of these results are conditioned upon the use of particular constructions of the generic factors and, as discussed above, there are many reasonable alternatives that could lead to very different findings. As a result, it is prudent to conclude that the simple use of style factors in currency investing is fraught with dangers and is of limited use as a benchmark for currency managers. There is no buy-and-hold or passive strategy benchmark to employ, so the issue of benchmarks for active currency investing remains problematic. Given this limitation of performance evaluation for FX compared to other asset classes, the next section suggests some analytical tools that may be of use. 


\section{Forecast Skill Evaluation: tilt and timing}

The prior section pointed out problems with identifying useful benchmarks for currency investing. Things are not hopeless here as one can think of skill along the lines of ability in timing important return-generating factors. This section will look at this issue in detail by focusing on active portfolio return decomposition along the following lines:

1. Analysing tilt and timing in active portfolios

2. Factor tilt and timing in active portfolios

Factors and portfolios from foreign exchange will be used to illustrate this.

For many active managers, measuring tilt and timing is important in evaluating the performance of trading strategies. Active managers are paid to take time varying positions in the markets in which they operate. Assume you have a portfolio manager who can trade two assets, an equity index and cash. The manager may expect to get a positive expected return through the equity risk premium by running a portfolio which is $100 \%$ long equities and $100 \%$ short cash. For most clients, this portfolio is easily and cheaply replicable, by buying an index tracking fund, for example. Investors will be inclined to pay higher fees for portfolios which are on average less correlated with these 'commoditised' portfolios: a fund which was long equities $50 \%$ of the time and long cash $50 \%$ of the time and provides alpha is highly desirable. The tilt and timing discussed in this section are special cases of the performance attribution shown in Chapter 17 of Grinold and Kahn (2000) and Lo (2007) where market factors are used in the 'static' or tilt portfolios.

\subsection{Analysing tilt and timing in active portfolios}

Let $h_{a, t}$ be a holding of an asset $a$ at time $t$ over $n$ periods. For each asset $a$, we define the tilt portfolio of $h_{a}$ to be the time series mean holding of $a$, i.e.

$$
\text { tilth }_{a}=\frac{\sum_{j=1}^{n} h_{a, j}}{n}
$$

At each point $t$ for each asset $a$ we define the timing portfolio as:

$$
\text { timh }_{a, t}=h_{a, t}-\text { tilth }_{a}
$$

This simple decomposition can be utilised to determine whether a particular signal has timing skill, or whether it is spending most of its risk in tilting. Given the decomposition shown above is in holdings space, we can simply convert the tilt and timing portfolios to returns space by multiplying by the asset returns. We then measure the 'skill' of the tilt and timing portfolios using standard analytics such as the information ratio on the returns from these portfolios.

Taking the equity / cash example above, a manager who was $100 \%$ long equities and $100 \%$ short cash at each point in time would have spent all its risk in tilting. The tilt portfolio would be equal to the overall portfolio and the timing portfolio would hold 0 positions in both assets. 
Using full sample time series means to determine the tilt exposure of a portfolio is a blunt tool. A further refinement of this analysis uses a moving window mean to determine the tilt portfolio. In the analysis below a backward looking window of 3 years of data ${ }^{15}$ is used.

We look at simple examples from the foreign exchange market. We use simple decision rules for succinctness. In fact, this can be thought of as a special case of the mean variance optimisation process described in Section 2, where in the utility function the alpha (or return forecast) is equal to the result of the decision rule, the covariance matrix $V$ is the identity matrix and the transaction cost function TC equals 0 .

\section{Example 1}

We generate a carry portfolio ${ }^{16}$ as follows:

1. At the end of every month, rank interest rates in G10 countries

2. For the next month hold a portfolio of $+30 \%$ currencies with the 3 highest interest rates, $-30 \%$ currencies with the 3 lowest interest rates

\section{Example 2}

We generate a trend portfolio ${ }^{17}$ as follows:

1. At the end of each month, rank G10 currencies by spot exchange rate appreciation (or depreciation) versus US Dollar over the previous 3 months (US Dollar equals $0)$. We will call this the period over which the foreign exchange appreciation or depreciation is measured the 'look back period'.

2. For the next month hold a portfolio of $+30 \%$ currencies which are highest ranked in step $1,-30 \%$ currencies the 3 currencies which are ranked lowest

Note that the choice of $30 \%$ positions in each of these examples is somewhat arbitrary, although they were used in the Deutsche Bank G10 Currency Future Harvest Index ${ }^{18}$. The

\footnotetext{
15 There is also an issue at the start point with a backward looking moving window. In the analysis below we have assumed no tilt until there are at least 36 monthly observations.

16 The carry strategy is a very well-known strategy in foreign exchange and has been written about extensively in both the practitioner and academic world. Burnside, Eichenbaum and Rebelo (2008) look at the impact of diversification on the carry trade; Burnside, Kleshchelski and Rebelo (2011) look at the relationship of the carry trade with Peso problems; Menkhoff, Sarno, Schmeling and Schrimpf (2012) look at the relationship of volatility and liquidity with the carry trade. Lustig, Roussanov and Verdelhan (2011) show empirical results associating the carry trade with global risk as proxied by global equity market volatility.

17 Trend following (or momentum) strategies are not solely the province of the foreign exchange world. The work of Asness, Moskowitz and Pedersen (2009) shows weak momentum effects in most asset classes. In foreign exchange in particular, Menkhoff and Taylor (2007) give a comprehensive description of trend following strategies used in the market, and Lequeux and Acar (1998) show that three trend following rules can help to replicate the trend following style of some investment managers. Burnside, Eichenbaum and Rebelo (2011) investigate why trend following strategies and carry strategies are successful. Menkhoff, Sarno, Schmeling and Schrimpf (forthcoming) show that while momentum does appear to be a meaningful factor in the foreign exchange markets, it is not easily exploitable.

${ }^{18}$ See, for example, https://index.db.com/dbiqweb2/home.do?redirect=search\&search=currency+harvest
} 
information ratio, the preferred measure of skill in active portfolio management, is insensitive to the size of the positions chosen here. As mentioned earlier, the information ratio is a ratio of annualized active return to annualized tracking error, where the active return is measured as the difference between actual return and a relevant financial benchmark. In Treynor and Black (1973) this is called the appraisal ratio. This is similar in spirit to the Sharpe ratio (Sharpe (1994)) where the ratio is annualized excess return to annualized tracking error, where excess return is measured as the asset return minus the risk free rate.

The information ratio is not the only analytic which is used to ascribe skill to a trading strategy. Also important is the consistency of the forecast of returns, so cumulative return plots are also heavily relied upon in the practitioner community. Statistically, the standard error bands on these charts are generally very wide, but the ability to forecast returns consistently is highly valued by clients.

Figure 4 shows the cumulative returns to the tilt, timing and overall strategies. The performance is calculated from January 1978 to December 2010.

$<$ Figure 4 goes here>

The carry portfolio spends most of its risk in a tilt, whereas the trend portfolio spends most of its risk in timing. The carry signal is equally effective (performance wise) in tilt and timing, whereas the trend signal shows only timing skill.

The trend signal construction above uses a 3 month look back period. We vary the look back period below using 1, 2, 3 and 6 months look back parameters. The table below shows the information ratio of these different strategies:

'Look back' Information Ratio

$1 \mathrm{~m} \quad 0.18$

$2 m \quad 0.29$

$3 \mathrm{~m} \quad 0.51$

$6 \mathrm{~m} \quad 0.20$

The 3 month look back period dominates in terms of signal performance. In general, an active manager tries to avoid cherry picking parameters that maximize the backtest performance: the poor performance using different parameterisations should act as a warning sign. Indeed, only the 3 month 'look back' parameterisation shows statistical significance. The work of Kahnemann (2011), for example, shows the dangers of investment managers who believe their own skill over the statistical properties of their trading strategies. Below we look to see whether there is any more consistent information we can find from these trend portfolios.

We can combine the trend and carry strategies to build a more complex strategy. Simply looking at the correlation of the returns from the two different strategies shows they should be additive: 
$1978-2010$

$1978-1994$

$1994-2010$

\section{Carry / trend correlation}

$-10 \%$

$-7 \%$

$-13 \%$

We could optimise weights over the backtest period to generate an optimal information ratio for the composite strategy, but for these purposes we will simply take an equal weighted portfolio of the 2 strategies, and again calculate the tilt timing analysis: the equally weighted trend and carry portfolio is denoted composite in the table below. Figure 5 displays the cumulative returns to the strategy.

\begin{tabular}{crrrrrr} 
& \multicolumn{2}{c}{ Annualised risk } & \multicolumn{3}{c}{ Information ratio } \\
Composite & tilt & Timing & Composite & tilt & Timing \\
Composite & $11.31 \%$ & $7.57 \%$ & $8.55 \%$ & 0.80 & 0.32 & 0.71
\end{tabular}

The composite strategy shows more timing skill than either the trend or carry signal. An active manager should provide a diversified set of insights and factors in a portfolio.

\subsection{Factor tilts and timing}

Pojarliev and Levich (2008) have shown that many active foreign exchange managers have tilts into standard FX factors (a definition of factor tilt will be given below), the trend and carry factors described above are two such factors. This means that clients are able to replicate the returns for some currency managers using 'off the shelf' currency indices and products, which will have cheaper fees than most active managers. Hedge fund replication has not only been investigated in low dimensional strategies, there has been something of an industry in this area over the last few years. ${ }^{19}$ Given the dimensionality of the bet in a G10 foreign exchange portfolio ( 9 degrees of freedom in the portfolio), Melvin and Shand (2011) argue that one should expect to see time varying exposures to these factors and that part of an active foreign exchange manager's job is to time these factors. Melvin and Shand (2011) show that even with few insights (they look at a carry portfolio, trend portfolio and value portfolio) it is possible to get negative loadings on a factor at certain points in time. It is important for clients to see time variation in the factor loadings (and indeed in loading negatively on a factor) to ensure that managers do not rely on easily replicable commoditised strategies.

To see how factors time-vary in a portfolio, we simply use the cross sectional correlation of holdings for the portfolio and the factor portfolio at each point in time $t$ over $n$ time periods:

$$
x s_{t}=\operatorname{corr}\left(\text { portfolio }_{t}, \text { factor }_{t}\right)
$$

We can define the factor tilt as the mean of the $x s_{t}$, i.e.

\footnotetext{
${ }^{19}$ See Amenc, El Bied, and Martellini (2003); Kat and Palaro (2005); and Hasanhodzic and Lo (2007) as an introduction to the work in this area.
} 


$$
\text { factortilt }=\frac{\sum_{j=1}^{n} x s_{j}}{n}
$$

And the factor timing portfolio at time $t$ as:

$$
\text { factortime }_{t}=x s_{t}-\text { factortilt }
$$

We can again measure the risk and information ratio of the factor tilt and timing portfolios $^{20}$.

We now investigate the interaction of the trend and carry portfolios from above. We have ascribed timing skill to the trend signal and observed that the carry portfolio generates a considerable amount of its return from a simple tilt. The question we investigate is whether we can time the carry portfolio with information from the trend portfolio.

Figure 6 shows the exposure of the trend signal to the carry factor. The factor tilt in this portfolio is 0.03 , although clearly from the chart at points in time there can be very high and very low exposure to the factor.

\begin{tabular}{lccc} 
& Annualised Return & Annualised Risk & Information Ratio \\
\cline { 2 - 4 } Factor Tilt & $0.14 \%$ & $0.25 \%$ & 0.57 \\
Factor Timing & $1.76 \%$ & $4.54 \%$ & 0.39
\end{tabular}

The risk and return statistics here are summary statistics over the whole sample. We look at a more nuanced view of the timing ability of the trend signal now using the time varying cross sectional correlation data.

We break up the carry portfolio returns into quintiles based on the correlation with the trend signal and calculate annualised return, annualised risk and the ratio of the return and risk. Note that these quintiles are formed ex-post, i.e. we would not be able to do this in real time. Quintile 1 corresponds to the periods where we have the lowest (most negative) correlation of the trend portfolio with the carry portfolio.

\section{$\begin{array}{llll}\text { Quintile } 1 & \text { Quintile 2 } & \text { Quintile } 3 \quad \text { Quintile 4 } & \text { Quintile 5 }\end{array}$}

Annualised

return

$$
-0.4 \%
$$

$5.6 \%$

$5.2 \%$

$9.1 \%$

$8.1 \%$

Annualised

risk

$12.1 \%$

$7.2 \%$

$7.2 \%$

$7.4 \%$

$8.4 \%$

\footnotetext{
${ }^{20}$ Clearly the information ratio for the factor tilt will be the same as the information ratio for the factor itself.
} 
This indicates that the trend signal has some timing information for the carry signal. If we extend this analysis to the momentum signals which were parameterised with different look back periods in the section above, we see that the general momentum strategy appears to have timing ability for the carry strategy. The cells in the table below show the annualised return to annualised risk ratio as above:

Look back period Quintile 1 Quintile 2 Quintile 3 Quintile 4 Quintile 5

$\begin{array}{lrrrrr}1 \mathrm{~m} & 0.50 & 0.52 & 0.58 & 0.72 & 0.62 \\ 2 \mathrm{~m} & 0.17 & 0.78 & 1.01 & 0.54 & 1.34 \\ 3 \mathrm{~m} & -0.03 & 0.78 & 0.72 & 1.23 & 0.96 \\ 6 \mathrm{~m} & 0.30 & -0.03 & 0.87 & 1.15 & 0.56\end{array}$

Foreign exchange investors need to show skill in managing their portfolios. Here we have reviewed one measure of skill: tilt and timing performance. The measurement of exposure to known factors such as carry is also a valuable tool. These factor exposures can be, as shown in the trend and carry example, incidental at any particular point in time even if, on average, there is little exposure to the factor. The ability to time the factor is therefore important. 


\section{Enhancing Forecasts with Conditioners}

Currency investors employ forecasts with the aim of generating attractive risk-adjusted returns. In the prior section we saw that a static tilt into the carry trade can generate longrun profitable strategies. In fact, if one believed the Meese-Rogoff result of a random walk being the best forecast of future spot returns in currencies, this might imply that the carry trade is a reasonable investment strategy as you never should expect the exchange rate to change from the current spot rate. But empirical analysis teaches that the ability to profit from interest differentials without offsetting exchange rate movements is threatened by exchange rate volatility. So even if one accepts that a random walk is the best forecast at a point in time looking forward, ex-post, we know that exchange rates will change from the current spot rate so that the greater the expected volatility, the greater the threat to a successful carry strategy. We should expect carry trades to deliver positive returns in normal market conditions but underperform in periods of financial market stress, when volatility spikes. The best investors have skill in timing factors, dialing risk up when a strategy outperforms and turning risk down when drawdown periods are realized, so in the case of carry trades, a measure of market stress can be a useful input into investing. Melvin and Taylor (2009) developed such a stress index and showed that it offered potential for enhancing returns to the carry trade. Such a general financial stress index (FSI) is similar in some respects to the index recently proposed by the International Monetary Fund (IMF) (IMF, 2008). ${ }^{21}$ However, an important difference between the FSI and the IMF version is that in operationalizing the FSI we do not use full-sample data in constructing the index (e.g. by fitting generalised autoregressive conditional heteroskedasticity, GARCH, models using the full-sample data or subtracting off full-sample means). This is important as investors do not have the advantage of perfect foresight in calibrating models and must, therefore, analyze models using only what is known in real time in each period. The FSI is built for the same group of seventeen developed countries as in the IMF study, namely: Australia, Austria, Belgium, Canada, Denmark, Finland, France, Germany, Italy, Japan, Netherlands, Norway, Spain, Sweden, Switzerland, the UK and the USA. In contrast to the IMF analysis, however, we built a 'global' FSI based on an average of the individual FSI for each of these seventeen countries.

The FSI is a composite variable built using market-based indicators in order to capture four essential characteristics of a financial crisis: large shifts in asset prices, an abrupt increase in risk and uncertainty, abrupt shifts in liquidity and a measurable decline in banking system health indicators.

In the banking sector, three indicators were used:

i) The beta of banking sector stocks, constructed as the twelve-month rolling covariance of the year-over-year percent change of a country's banking sector equity index and its overall stock market index, divided by the rolling twelvemonth variance of the year-over-year percent change of the overall stock market index.

\footnotetext{
${ }^{21}$ See also Illing and Liu (2006).
} 
ii) The spread between interbank rates and the yield on Treasury Bills, i.e. the socalled TED spread that we discussed above: three-month LIBOR or commercial paper rate minus the government short-term rate.

iii) The slope of the yield curve, or inverted term spread: the government shortterm Treasury Bill yield minus the government long-term bond yield.

In the securities market, a further three indicators were used:

i) Corporate bond spreads: the corporate bond yield minus the long-term government bond yield.

ii) Stock market returns: the monthly percentage change in the country equity market index.

iii) Time-varying stock return volatility. This was calculated as the square root of an exponential moving average of squared deviations from an exponential moving average of national equity market returns. An exponential moving average with a 36-month half-life was used in both cases.

Finally, in the foreign exchange market:

iv) For each country a time-varying measure of real exchange rate volatility was similarly calculated - i.e. the square root of an exponential moving average of squared deviations from an exponential moving average of monthly percentage real effective exchange rate changes. An exponential moving average with a 36-month half-life was used in both cases.

All components of the FSI are in monthly frequency and each component is scaled to be equal to 100 at the beginning of the sample. A national FSI index is constructed for each country by taking an equally weighted average of the various components. Then, a global FSI index is constructed by taking an equally weighted average of the seventeen national FSI indices. The calculated global FSI series runs from December 1983 until October $2008 .^{22}$

In order to ascertain whether an extreme value of the FSI has been breached, we scored the FSI by subtracting off a time-varying mean (calculated using an exponential moving average with a 36-month half-life) and dividing through by a time-varying standard deviation (calculated taking the square root of an exponential moving average, with a 36month half-life, of the squared deviations from the time-varying mean). The resulting scored FSI gives a measure of how many standard deviations the FSI is away from its time-varying mean.

As can be seen from Figure 7, the global FSI crosses the threshold of one standard deviation above the mean for most of the major crises of the past twenty years or so, including the 1987 stock market crash, the Nikkei/junk bond collapse of the late 1980s, the 1990 Scandinavian banking crisis and the 1998 Russian default/LTCM crisis. The 1992 ERM crisis is less evident at the global level.

\footnotetext{
${ }^{22}$ No doubt, one can fine-tune the FSI in terms of weighting components and countries as a function of contribution to performance. Here we follow the IMF approach, but for any particular application, one could probably extend the analysis and achieve some marginal improvement in results.
} 
Most interestingly, however, the global FSI shows a very marked effect during the recent crisis. Mirroring the carry unwind in August 2007 that we documented above, there is a brief lull in the FSI as it drops below one standard deviation from its mean before leaping up again in November 2007 to nearly 1.5 standard deviations from the mean. The global FSI then breaches the two-standard deviation threshold in January 2008 and again in March 2008 (coinciding with the near collapse of Bear Stearns). With the single exception of a brief lull in May 2008, when the global FSI falls to about 0.7 standard deviations above the mean, it then remains more than one standard deviation above the mean for the rest of the sample, spiking up in October to more than four standard deviations from the mean following the Lehman Brothers debacle in September. ${ }^{23}$

It is tempting to infer from this analysis that an active currency manager could have significantly defended their portfolio by taking risk off (or perhaps even going short carry) in August 2007, especially as the carry unwind that occurred that month is confirmed as a crisis point by the movements in the global FSI in the same month. We carried out a first exploration of this idea by estimating a Probit model of significant drawdowns from the carry trade investment as a function of the global FSI, where a "significant drawdown" is defined as greater than a one standard deviation negative return. Table 4 presents the specification and estimation results. Clearly, the probability of a major drawdown from a carry trade investment is increasing in the FSI. Table 4 yields evidence of statistical significance of the effect of the FSI on the carry trade. ${ }^{24}$ What about economic significance?

To examine the economic significance of the FSI effects on carry trade returns, we simulate the returns an investor would earn from investing in the Deutsche Bank Carry Return Index (long the 3 highest yielding currencies and short the 3 lowest yielding currencies across the developed markets). Suppose the investor just invests in the index in an unconditional sense, without regard to market conditions. We will call this the "Unconditional Return." Alternatively, the investor can invest in the index in "normal" periods and close out the position in stressful periods, where stress is measured by the global FSI. Specifically, when the FSI exceeds a value of 1, the carry trade exposure is shut off; otherwise, the investment is held. Figure 8 illustrates the cumulative returns to such strategies. The cumulative unconditional return is $-1 \%$ while the conditional return is $+38 \%$ over the period studied. ${ }^{25}$

\footnotetext{
${ }^{23}$ Apart from financial forecasting, a measure like the FSI could be useful for policymakers to gauge the stresses in financial markets to help inform monetary and fiscal decisions.

${ }^{24}$ A consideration of factors that might control carry trade losses is receiving increased attention in the literature lately. Some examples are Brunnermeier, Nagel, and Pedersen (2008); Jurek (2007); Clarida, Davis, and Pedersen (2009); Habib and Straccca (2012); and Jorda and Taylor (forthcoming).

${ }^{25}$ Recall that the FSI only uses information known at each point in time in the sample, there is no peekahead in the data. In addition, these results are achieved with the arbitrary choice of FSI threshold of one standard deviation with no specification search over alternative cut-offs,
} 
Our carry-trade horse race clearly indicates a superior performance of conditioning the carry trade investment on the FSI. In more familiar investment metrics, over the entire 2000-2008 period studied, the unconditional strategy yielded an information ratio (IR, measuring return per unit of risk) equal to -0.03 while the conditional return yields an IR of 0.69. Over the more recent 2005-2008 period, the unconditional IR is - 0.66 while the conditional IR is 0.31 . In this regard, we see that the FSI as a risk indicator has potential value to $\mathrm{FX}$ investments.

Caveats regarding this analysis are as follows:

1) These results ignore transaction costs. This is important as when the FSI signals significant stress, market conditions are such that we should observe widespread carry trade unwinding. So an investor will face large one-sided market conditions that will lead to a much greater than normal cost of trading. Furthermore, investors seeking to sell out of their carry positions will face very thin offers on the other side of their trade. For instance, to close out the carry trade strategy of short yen (JPY), long New Zealand dollar (NZD) would involve buying JPY and selling NZD. But if there is great interest to do the same trade across the market, there will be very little flow interested in selling JPY and buying NZD, so market makers will price trades accordingly so that the price of exiting the carry trade will be much higher than in normal times.

2) These results assume the carry trade exposure is eliminated in the same month that the FSI signals stress. There may be a lag between recognition of the market stress and exiting the position. If the carry trade exposure is eliminated in the month following the FSI signal of stress, the IR falls from 0.69 to 0.42 over the entire 2000-2008 sample period and from 0.66 to 0.00 over the recent $2005-2008$ period. If the investor cannot recognize the shift to the stressful state in real time, it may be too late in many cases to reduce carry trade exposure. 


\section{Summary}

Investment managers seeking to build actively managed currency portfolios take a different approach to forecasting exchange rates than academics. Practitioners need return forecasts that correctly rank currencies from those most likely to appreciate to those least likely to appreciate. Popular approaches in the scholarly literature focus on minimizing forecast errors for bilateral exchange rates. Such approaches are interesting and useful for some purposes but are not necessary for successful currency investing. This chapter illustrates the difference using purchasing power parity as an exchange rate model. Section 3 offers a high-level outline of how one can employ exchange rate forecasts in a quantitative model to trade currencies. In addition to the return forecasts, a risk model and transaction cost model are needed to optimize the portfolio. By far, the most important input to the model is the exchange rate return forecasts. Performance evaluation for investment managers is different from the academic focus on forecast errors. Investment performance is typically evaluated relative to some benchmark portfolio return, like a broad market return in equity investing. However, in currency investing the issue of benchmarks is not quite so easy. Section 4 provides an analysis of the difficulties of employing generic style factors for currency investing to use as benchmarks. Identifying useful benchmarks for currency investors remains problematic and one should proceed with caution and skepticism when attempting such an exercise. If benchmarks are not readily available for evaluation of currency manager performance, there are additional tools that may be employed for assessment. Section 5 discusses tilt and timing analysis of portfolio returns, where the tilt is the return to a static portfolio through time - something which should not be well rewarded by clients. Investors should seek evidence of timing skill from good managers and pay for the ability to successfully time factors that generate alpha in currency markets. Finally, section 6 shows that it is possible to enhance timing skill by employing conditioning information that shifts weights on different factors through time. The particular example studied is the use of a financial stress indicator to time exposure to the carry trade. When financial stress is great, carry trade exposure is dialed down. This can significantly increase the return to the carry trade over the long-run. 


\section{References}

Amenc, N., El Bied, S., and Martellini, L., 2003. Predictability in hedge fund returns, Financial Analysts Journal. 59, 32-46.

Bessembinder, H., 1994. Bid-ask spreads in the interbank foreign exchange markets. Journal of Financial Economics. 35, 317-348.

Bollerslev, T., Engle, R.F., Wooldridge, J.M., 1988. A capital asset pricing model with time-varying covariances. Journal of Political Economy. 96, 116-131.

Bollerslev, T., Melvin, M., 1994. Bid-ask spreads and volatility in the foreign exchange market. Journal of International Economics. 36, 355-372.

Brunnermeir , M., Nagel, S., Pedersen, L., 2008. Carry trades and currency crashes. NBER Macroeconomics Annual, 2008.

Burnside, C., Eichenbaum, M., and Rebelo, S., 2008. Carry trade: the gains from diversification. Journal of the European Economic Association. 6(2-3), 581-588.

Burnside, C., Eichenbaum, M., and Rebelo, S., 2011. Carry trade and momentum in currency markets. Annual Review of Financial Economics. 3, 511-535.

Burnside, C., Kleshchelski, I., and Rebelo, S., 2011. Do peso problems explain the returns to the carry trade. Review of Financial Studies . 24, 853-891.

Cheung, Y., Chinn, M, and Pascual, A. G., 2005. Empirical exchange rate models of the nineties: are any fit to survive? Journal of International Money and Finance. 24, 11501175 .

Christensen, K., Kinnebrock, S., and Podolskij, M., 2010. Pre-averaging estimators of the ex-post covariance matrix in noisy diffusion models with non-synchronous data. Journal of Econometrics. 159, 116-133.

Clarida, R., Davis, J., Pedersen, N., 2009. Currency carry trade regimes: Beyond the Fama regression. Journal of International Money and Finance. 28, 1375-1389.

Della Corte, Pasquale, Sarno, Lucio, and Tsiakas, Ilias, 2009. An economic evaluation of empirical exchange rate models. The Review of Financial Studies. 22, 3491-3530.

De Zwart, G., Markwat, T., Swinkels, L. and van Dijk, D. 2009. The economic value of fundamental and technical information in emerging currency markets. Journal of International Money and Finance. 28, 581-604. 
Elliott, G. and Ito, T., 1999. Heterogeeneous expectations and test of efficiency in the yen/dollar forward exchange rate market. Journal of Monetary Economics. 43, 435-456.

Engel, C., Mark, N.C., and West, K.D., 2007. Exchange rate models are not as bad as you think. NBER Macroeconomics Annual. 381-441.

Evans, M.D.D., 2011. Exchange Rate Dynamics. Princeton Univ Press, Princeton.

Frankel, J.A. and Rose, A.K., 1995. Empirical research on nominal exchange rates. Handbook of International Economics. 3, Elsevier, Amsterdam.

Glassman, D. 1987. Exchange rate risk and transactions costs: Evidence from bid-ask spreads. Journal of International Money and Finance. 6, 479-490.

Grinold, R and Kahn, R., 2000. Active Portfolio Management. McGraw Hill, New York.

Habib, M.M. and Stracca, L., 2012. Getting beyond carry trade: What makes a safe haven currency? Journal of International Economics. 87, 50-64.

Hartmann, P. 1999. Trading volumes and transaction costs in the foreign exchange market: Evidence from daily dollar-yen spot data. Journal of Banking and Finance. 23, 891-824.

Hasanhodzic, J. and Lo, A., 2007. Can hedge fund returns be replicated?: The linear case. Journal oF Investment Management. 5, 5-45.

Illing, M. and Liu, Y., 2006. Measuring financial stress in a developed country: an application to Canada. Journal of Financial Stability. 2, 243-265.

James, J., 2003. Simple trend-following strategies in currency trading. Quantitative Finance. 3, C75-C77.

Jorda, O. and Taylor, A.M., forthcoming. The carry trade and fundamentals: Nothing to fear but FEER itself. Journal of International Economics.

Jorion, P., 1985. International portfolio diversification with estimation risk. The Journal of Business. 58, 259-278.

Jurek, J., 2007. Crash-neutral currency carry trades. Princeton, Bendheim Center for Finance. Working Paper.

Kahneman, D., 2011. Thinking fast and slow. Allen Lane, London.

Kat, H. and Palaro, H., 2005. Hedge fund returns: you can make them yourself! Journal of Wealth Management. 8, 62-68. 
Konno, H. and Yamazaki, H., 1991. Mean-absolute deviation portfolio optimization model and its applications to Tokyo stock market. Management Science. 37, 519-531.

Kroner, K.E. and Ng, V.K., 1998. Modeling asymmetric comovements of asset returns. Review of Financial Studies. 11, 817-844.

Ledoit, O. and Wolf, M., 2004. Honey, I shrunk the sample covariance matrix. The Journal of Portfolio Management. 30, 110-119.

Lequeux, P. and Acar. E., 1998. A dynamic index for managed currencies funds using CME currency contracts. European Journal of Finance. 4, 311-330.

Lo, A., 2002. The Statistics of Sharpe Ratios. Financial Analysts Journal. 58, 36-52.

Lo, A., 2007. Where do alphas come from?: A new measure of the value of active investment management. Journal of Investment Management. 6, 1-29.

Lustig, H., Roussanov, N and Verdelhan A., 2011. Common risk factors in currency Markets. Review of Financial Studies. 24, 3731-3777.

Meese, R. and Rogoff, K., 1983. Empirical exchange rate models of the seventies: Do they fit out of sample? Journal of International Economics. 14, 3-24.

Melvin, M. and Shand, D., 2011. Active currency investing and performance benchmarks. The Journal of Portfolio Management. 37, 46-59.

Melvin, M. and Taylor, M., 2009. The crisis in the foreign exchange market. Journal of International Money and Finance. 28, 1317-1330.

Menkhoff, L. and Taylor, M., 2007. The obstinate passion of foreign exchange professionals: Technical Analysis. Journal of Economic Literature. 45, 935-972.

Menkhoff, L., Schmeling, M., Sarno, L., and Schrimpf, A., 2012. Carry trades and global foreign exchange volatility. Journal of Finance. 67, 681-718.

Menkhoff, L., Schmeling, M., Sarno, L., and Schrimpf, A., Forthcoming. Currency momentum strategies. Journal of Financial Economics.

Naranjo, A., and Nimalendran, M., 2000. Government intervention and adverse selection costs in foreign exchange markets. The Review of Financial Studies. 13, 453-477.

Neely, C., Weller, P. and Ulrich, J. 2009. The adaptive markets hypothesis: Evidence from the foreign exchange market. Journal of Financial and Quantitative Analysis. 44, 467-488. 
Obstfeld, M, and Rogoff, K., 2001. The six major puzzles in international macroeconomics: is there a common cause? In Rogoff, $K$. and Bernanke, B., eds. ,NBER Macroeconomics Annual 2000. 15, MIT Press, p. 339-412.

Okunev, J. and White, D. 2003. Do momentum-based strategies still work in foreign currency markets? Journal of Financial and Quantitative Analysis. 425-447.

Paape, C. 2003. Currency overlay in performance evaluation. Financial Analysts Journal. 59, 55-68.

Pojarliev, M., Levich, R., 2008. Do professional currency managers beat the benchmark? Financial Analysts Journal. 64, 18-32.

Pojarliev, M. and Levich, R. 2010. Trades of the living dead: Style differences, style persistence and performance of currency fund managers. Journal of International Money and Finance. 29, 1752-1775.

Pojarliev, M. and Levich, R. 2011. Are all currency managers equal? Journal of Portfolio Management. 37, 42-53.

Ramadorai, T., 2008. What determines transaction costs in foreign exchange markets? International Journal of Finance and Economics. 13, 14-25.

Sarno, L. and Taylor, M.P., 2002. The economics of exchange rates. Cambridge Univ Press, Cambridge.

Satchell, S. and Timmermann, A., 1995. An assessment of the economic value of nonlinear foreign exchange rate forecasts. Journal of Forecasting. 14, 477-497.

Shanken, J., 1987. Nonsynchronous data and the covariance-factor structure of returns. Journal of Finance. 42, 221-231.

Sharpe, W. F., 1994. The Sharpe ratio. Journal of Portfolio Management. 21. 49-59.

Stevens, G., 1998. On the inverse of the covariance matrix in portfolio analysis, Journal of Finance. 53, 1821-1827.

Taylor, M.P., 1995. The economics of exchange rates. Journal of Economic Literature. 33, $13-47$.

Treynor, J. and Black, F., 1973. How to use security analysis to improve portfolio selection. Journal of Business. 46, 66-86.

Williamson, J. 2009. Exchange rate economics. Open Economies Review. 20, 123-14 


\section{Figures}

\section{Figure 1}

Spot rates and fair value according to purchasing power parity

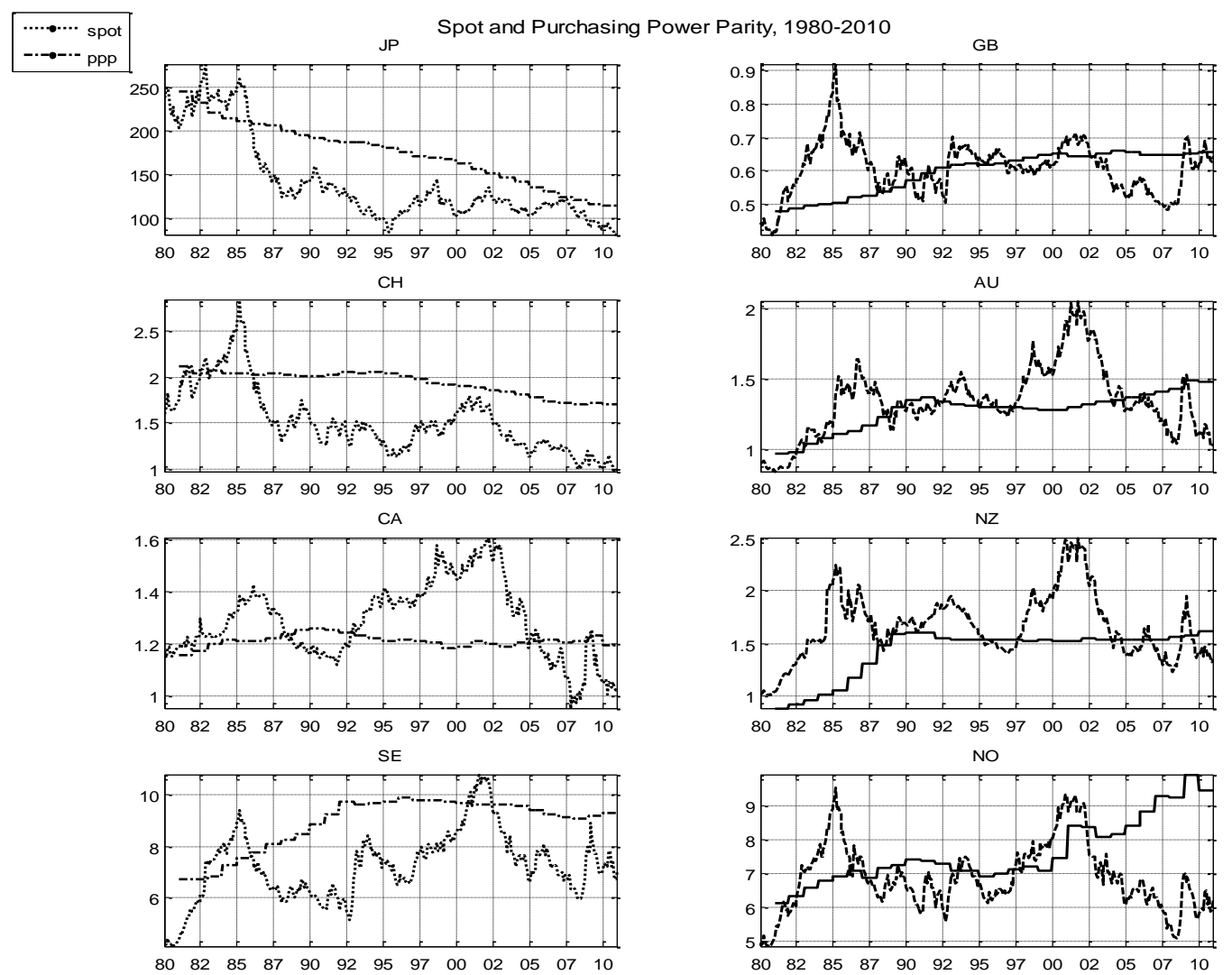




\section{Figure 2}

\section{Performance of portfolio of currencies ranked by deviation from PPP}

This portfolio is rebalanced monthly at the beginning of each month, beginning in 1981:1 and ending in 2010:12. It is a sum-to-zero, long-short portfolio with positions in the US dollar, Japanese yen, British pound, Swiss franc, Canadian dollar, Australian dollar, New Zealand dollar, Swedish krona and Norwegian kroner. The information ratio of the portfolio's performance over the full sample is 0.5 .

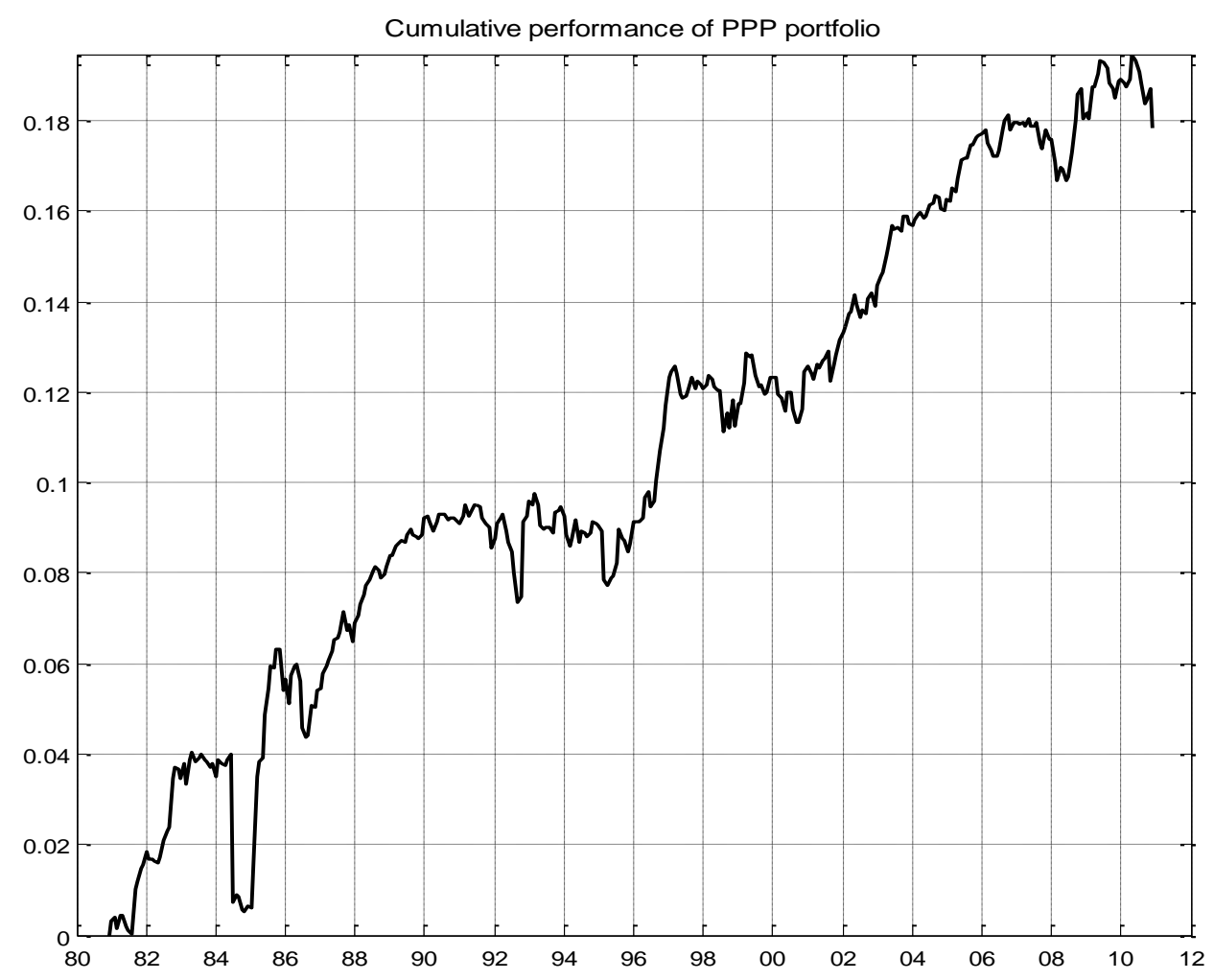




\section{Figure 3}

\section{Cumulative Returns to Trend Following Strategies}

The figure displays the cumulative returns to momentum or trend investment strategies offered by indexes created by AFX, Credit Suisse, and Deutsche Bank.

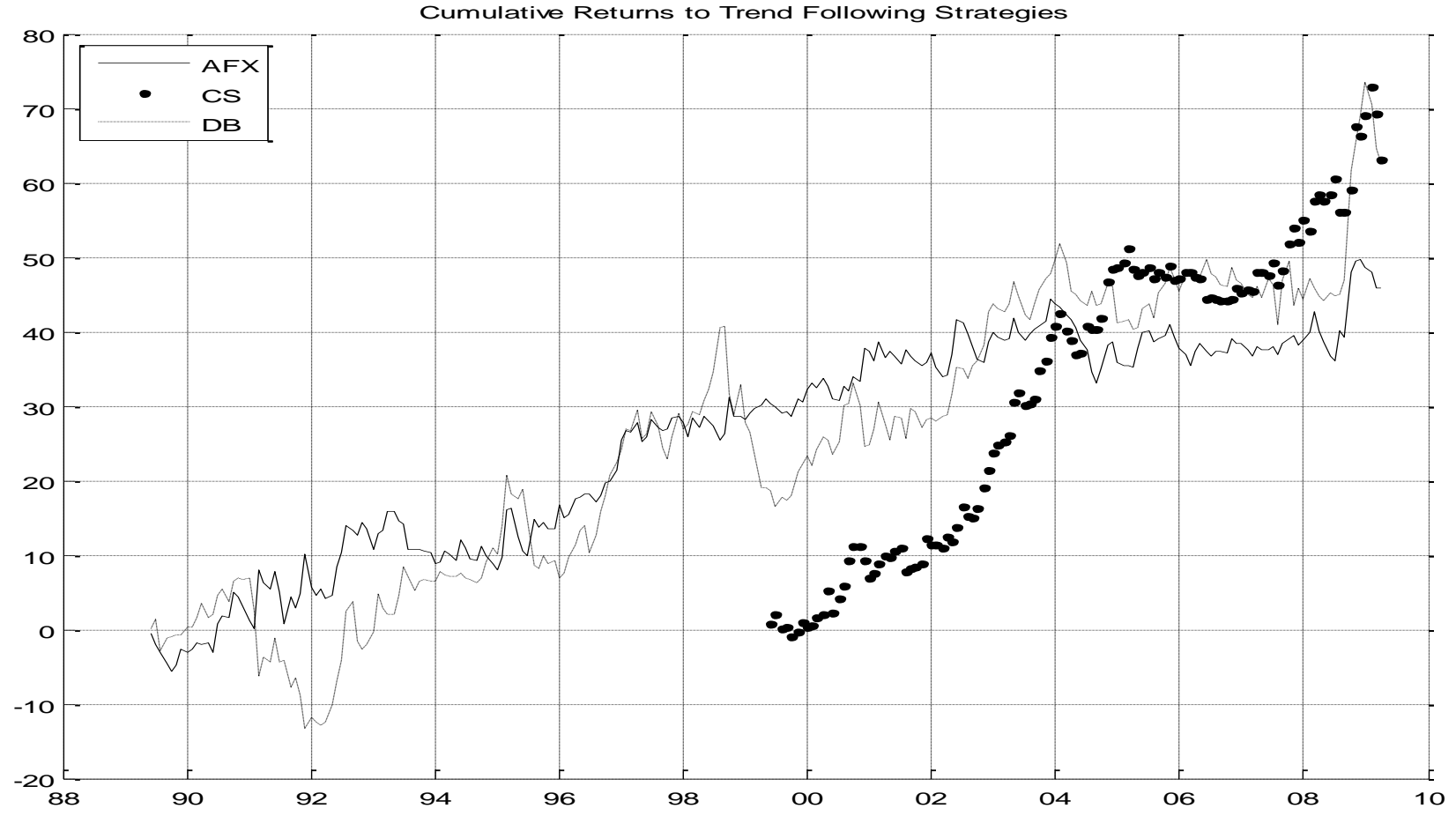




\section{Figure 4}

Cumulative Returns to Trend and Carry Strategies and the Decomposition into Tilt and Timing Returns
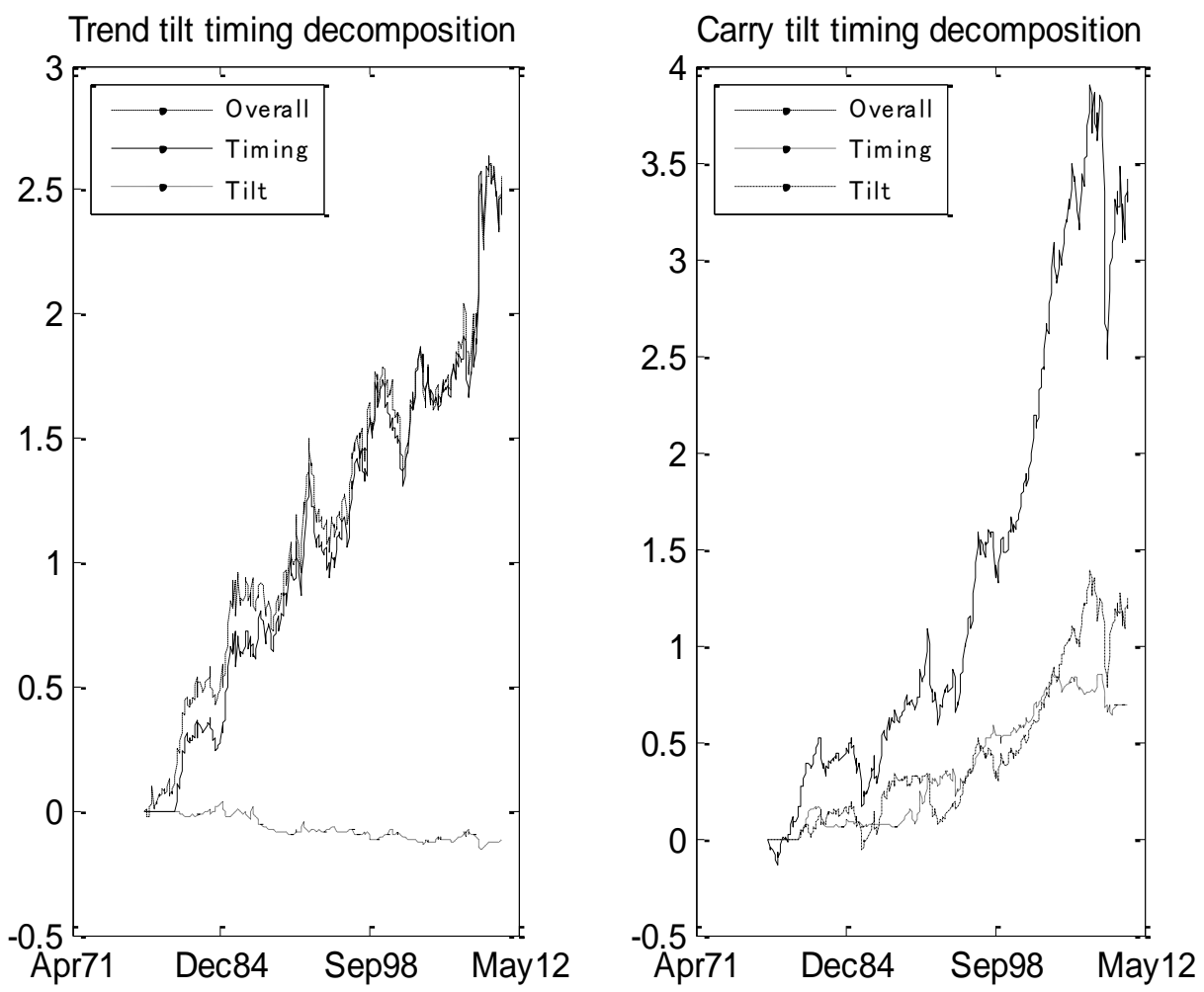

Annualised risk

Information ratio

Overall strategy tilt Timing

Overall strategy tilt Timing

carry

$8.64 \% 7.42 \% 4.09 \%$

$\begin{array}{lll}0.57 & 0.43 & 0.43\end{array}$

trend

$8.19 \% 2.27 \% 7.71 \%$

$0.51-0.16 \quad 0.56$ 


\section{Figure 5}

Cumulative Returns to Combining Trend and Carry Strategies and the Decomposition into Tilt and Timing Returns

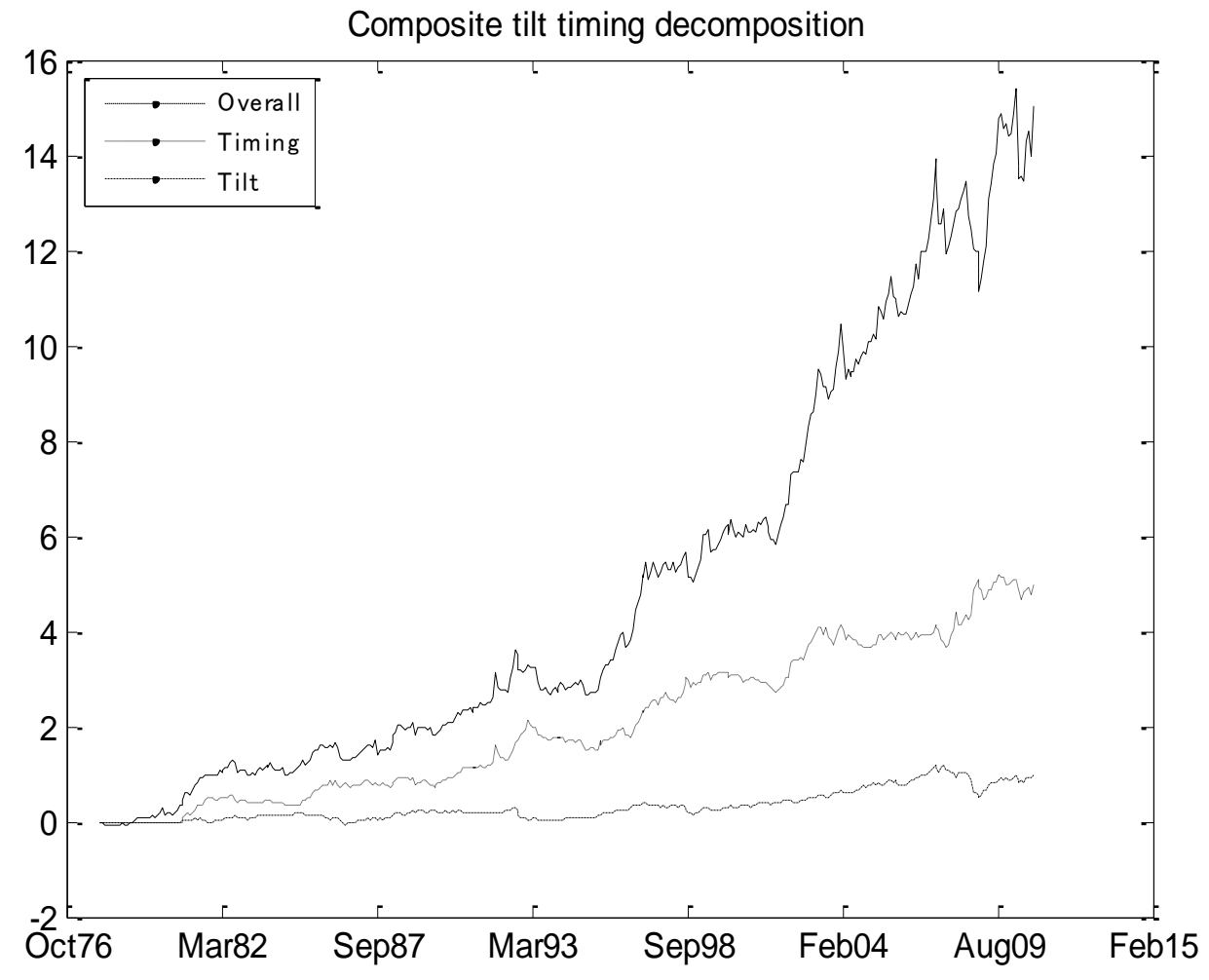




\section{Figure 6}

The Exposure of the Trend Signal to the Carry Factor

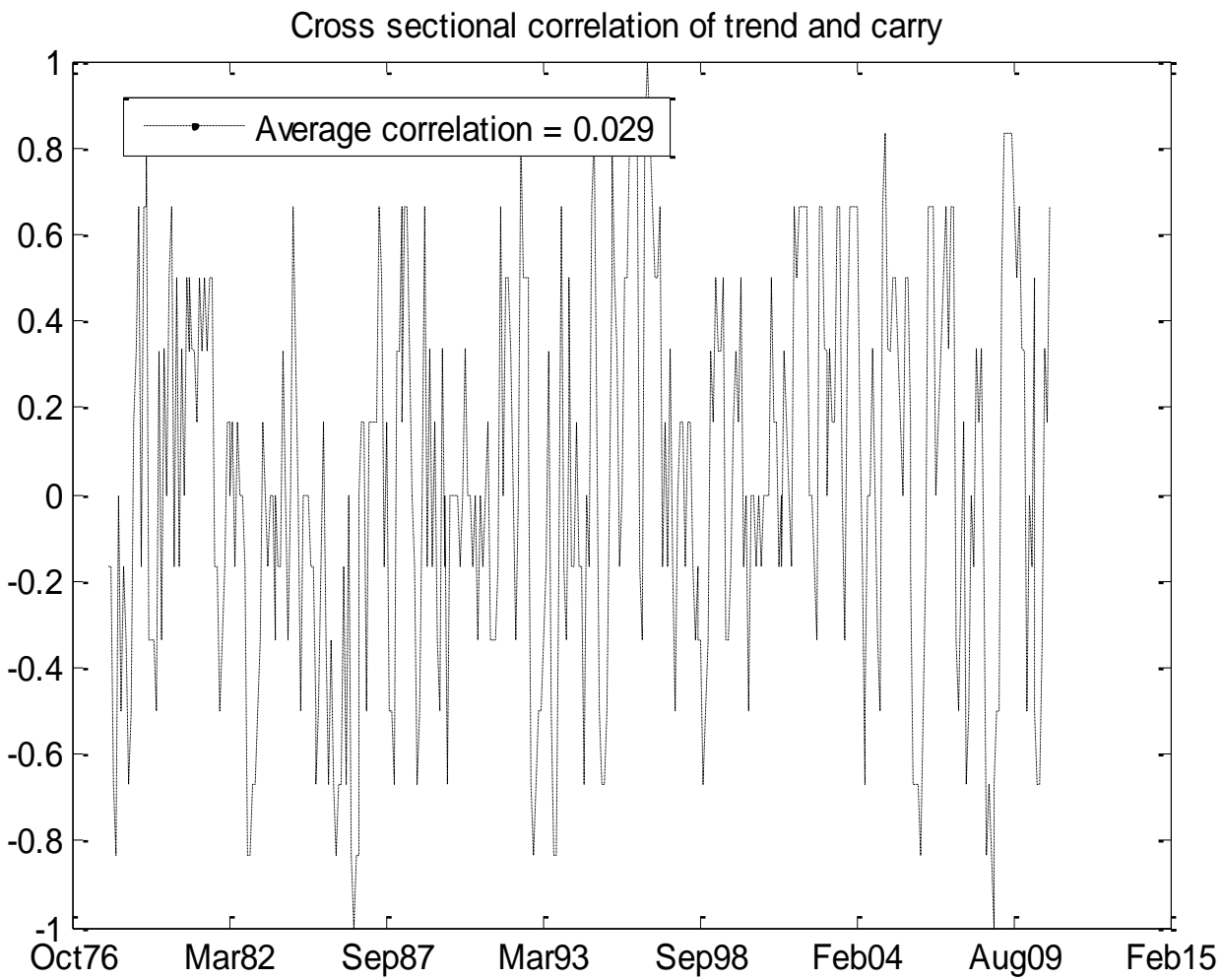


Figure 7

\section{The Global Financial Stress Index}

As a standard normal variable, one can see when financial stress is at extremes (greater than 1 standard deviation)

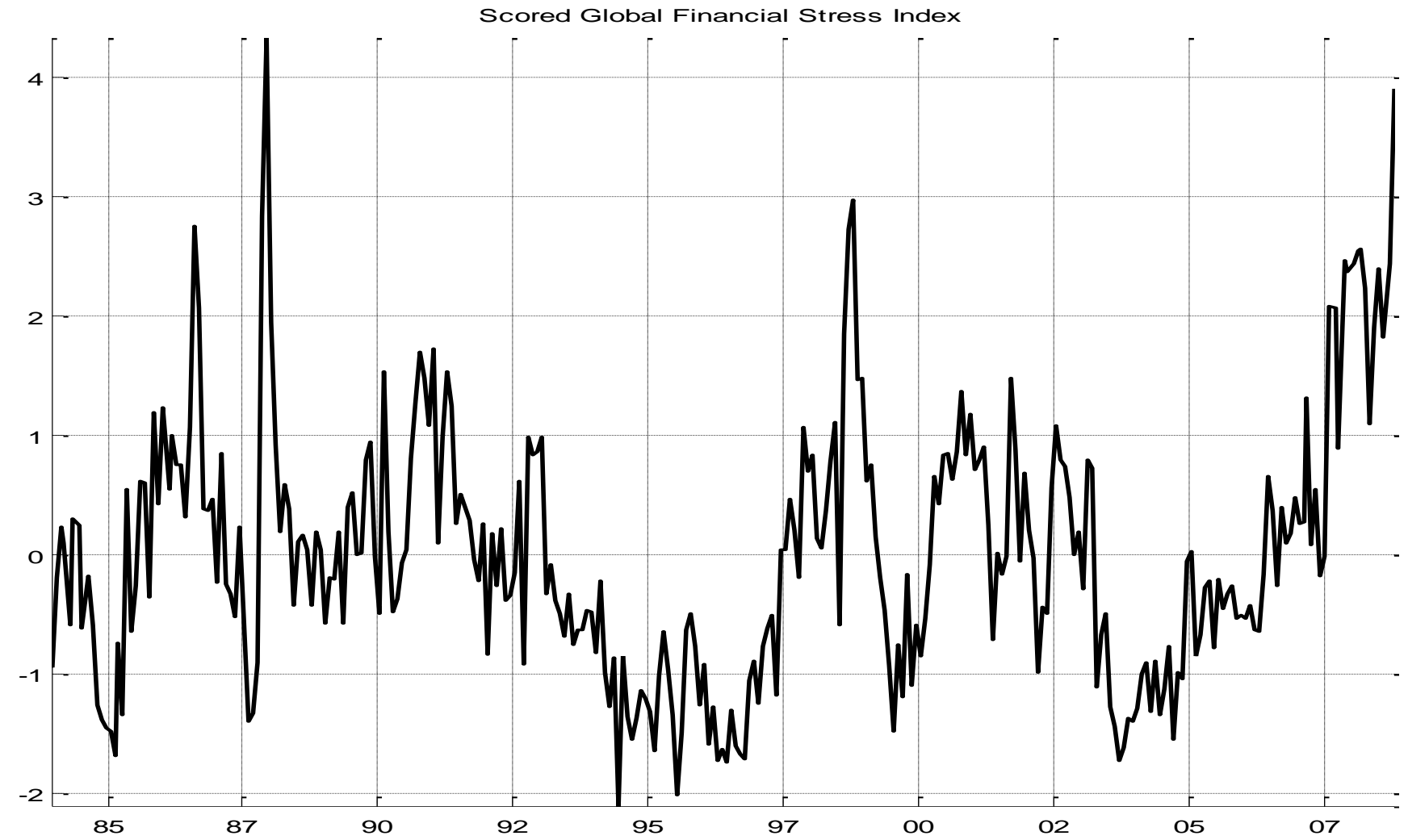




\section{Figure 8}

\section{The Returns to the Carry Trade}

The graph illustrates the cumulative returns to an investment in the Deutsche Bank Carry Index. In the unconditional case, the investor simply maintains the investment regardless of market conditions. In the conditioned case, the investment is shut off when the Global FSI index of financial market risk signals a particularly stressful period.

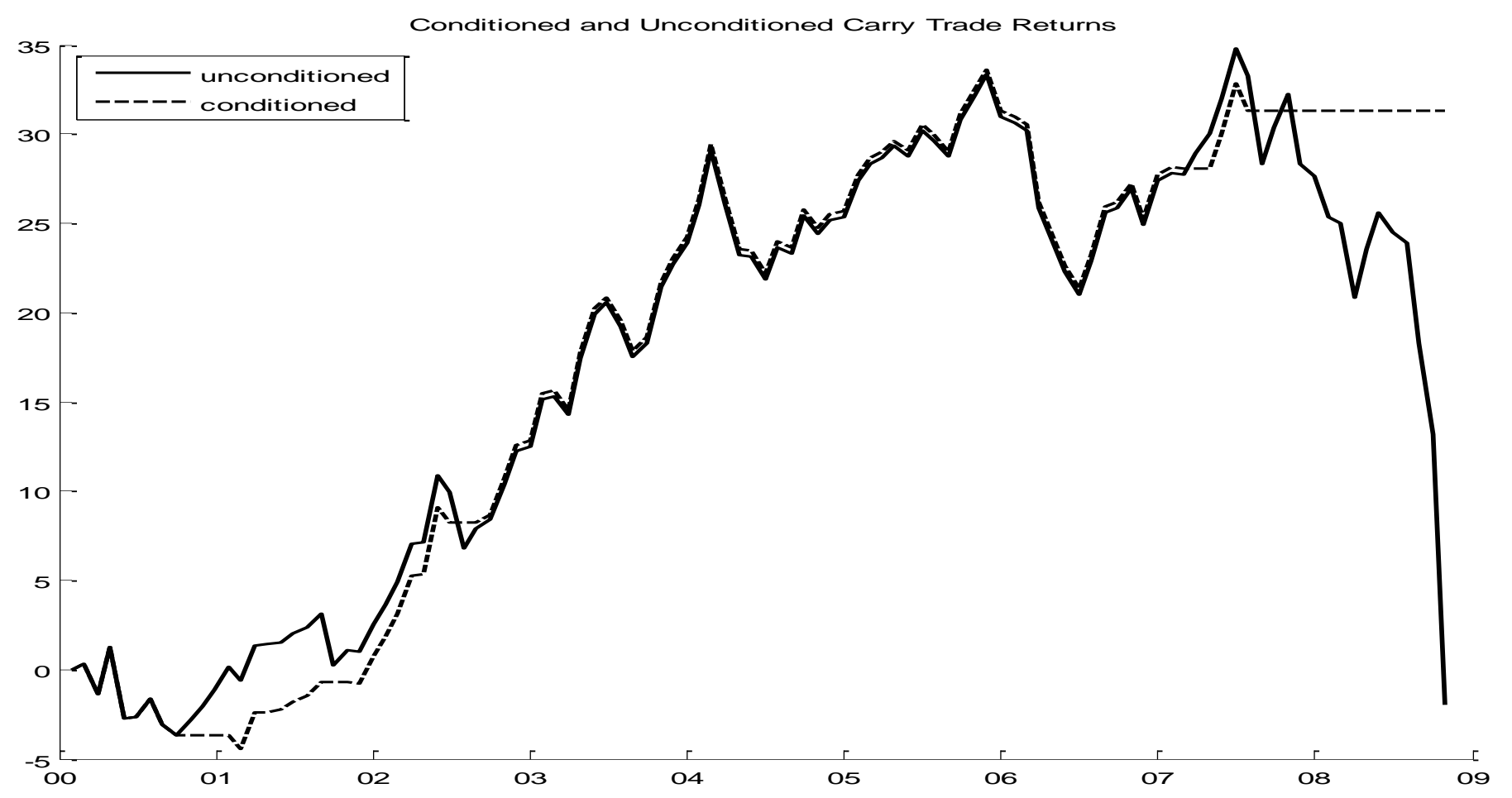




\section{Tables}

Table 1

\section{Out-of-sample tests for predictability in exchange rates}

This table shows the results of the test for out-of-sample predictability of exchange rates by the forecasts based on our measure of deviations from purchasing power parity. Forecasts are monthly for each currency from 1981:1 to 2010:12 (30 years), and in each month are based on PPP values from the year before, and spot values from the month before. For the Diebold-Mariano and Theil's U tests, critical values are obtained by bootstrapping with 1000 iterations.

\begin{tabular}{|c|c|c|c|c|c|c|c|c|}
\cline { 2 - 9 } \multicolumn{1}{c|}{} & \multicolumn{2}{c|}{ Clark-West } & \multicolumn{2}{c|}{ Clark-McCracken } & \multicolumn{2}{c|}{ Diebold-Mariano } & \multicolumn{2}{c|}{ Theil U } \\
\cline { 2 - 10 } \multicolumn{1}{c|}{} & stat & $\mathrm{p}$-value & stat & $\mathrm{p}$-value & stat & p-value & stat & $\mathrm{p}$-value \\
\hline PANEL & 1.35 & 0.00 & 24.50 & 0.00 & -0.199308 & 0.25 & 7.2336 & 0.36 \\
\hline $\mathrm{AU}$ & 0.35 & 0.13 & 1.79 & 0.14 & -0.226382 & 0.37 & 7.5708 & 0.42 \\
\hline $\mathrm{CA}$ & 0.74 & 0.10 & 6.77 & 0.03 & -0.155681 & 0.40 & 6.0734 & 0.40 \\
\hline $\mathrm{CH}$ & 0.09 & 0.46 & 0.46 & 0.41 & -0.232425 & 0.42 & 7.5860 & 0.45 \\
\hline $\mathrm{GB}$ & 0.79 & 0.15 & 5.86 & 0.08 & -0.158947 & 0.39 & 5.8255 & 0.37 \\
\hline $\mathrm{JP}$ & 0.53 & 0.31 & 2.74 & 0.29 & -0.122087 & 0.47 & 7.2544 & 0.46 \\
\hline $\mathrm{NO}$ & 0.84 & 0.28 & 4.39 & 0.13 & -0.300458 & 0.47 & 9.3426 & 0.48 \\
\hline $\mathrm{NZ}$ & 0.43 & 0.17 & 2.67 & 0.17 & -0.188990 & 0.35 & 6.7386 & 0.37 \\
\hline $\mathrm{SE}$ & 0.12 & 0.27 & 0.90 & 0.24 & -0.153080 & 0.40 & 5.9143 & 0.41 \\
\hline
\end{tabular}


Table 2

\section{FX Bid-Ask Spreads for \$50-100 million}

Values are for risk-transfer trades in the range of \$50-100 million, where a counterparty requests a two-way price from a market-maker in a bilateral transaction. These should be considered representative in a low volatility period. Larger trades would generally have wider spreads. Values are in "pips," for instance if the spread on EURUSD is 1, then the spread would be something like 1.3530-1.3531. Both spot and 3-month forward swap spreads are given.

\begin{tabular}{|c|c|c|}
\hline & spot & 3-mo swap \\
\hline EURUSD & 1 & 0.2 \\
\hline GBPUSD & 3 & 0.3 \\
\hline USDJPY & 3 & 0.2 \\
\hline USDCHF & 4 & 0.4 \\
\hline AUDUSD & 4 & 0.4 \\
\hline USDCAD & 4 & 0.3 \\
\hline NZDUSD & 8 & 0.5 \\
\hline
\end{tabular}


Table 3

\section{Correlations Across Currency Performance Benchmarks}

The table reports correlations across alternative factor indexes that are frequently employed by active currency managers: trend or momentum, carry, and value. The indexes are provided by Deutsche Bank (DB), Credit Suisse (CS), the Centre for International Banking Economics and Finance (AFX), and Citibank (Citi).

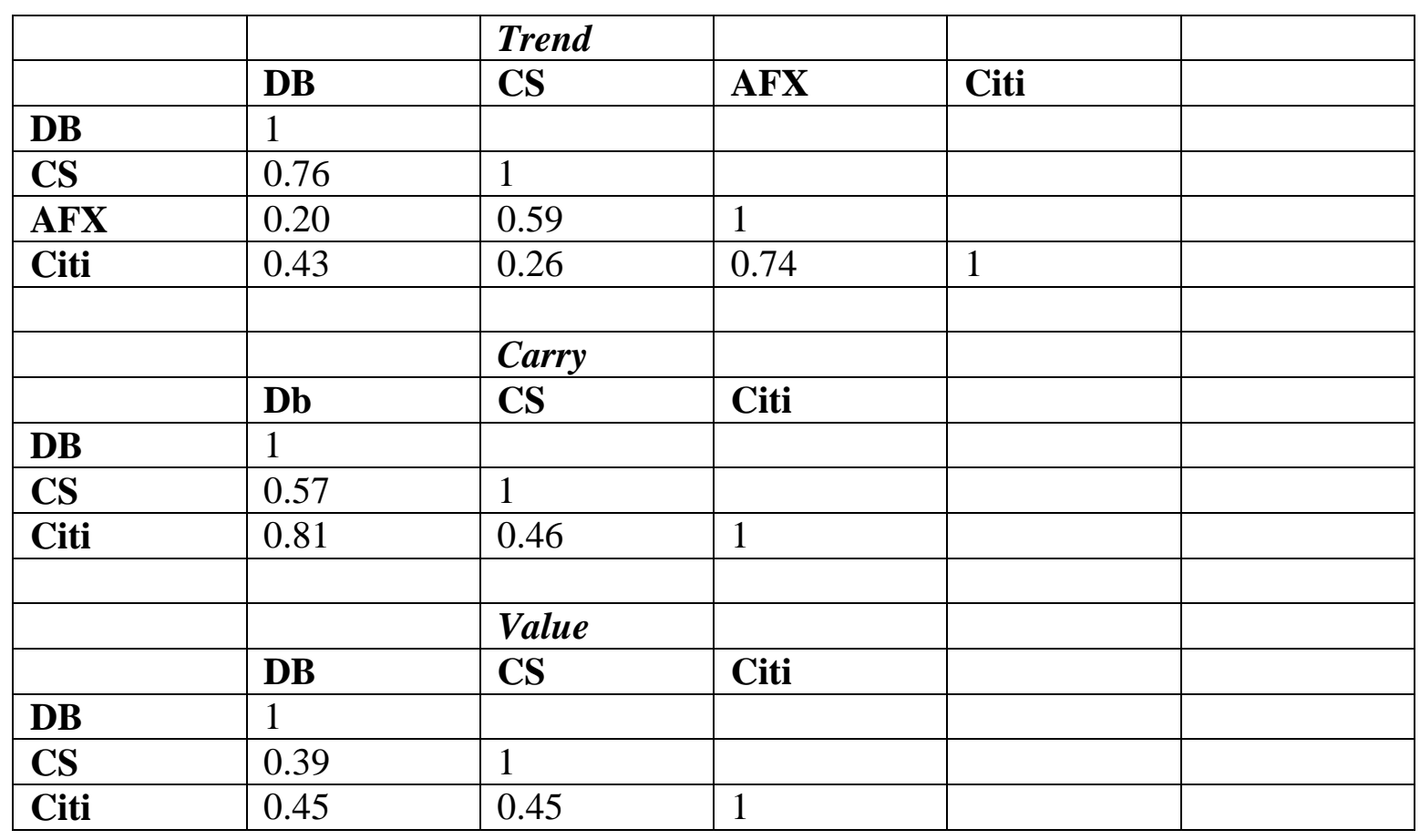


Table 4

\section{Carry Trade Investment Drawdowns and the Financial Stress Index}

The table reports results of a Probit regression estimation of periods of significant negative returns to an investment in the Deutsche Bank Carry Index as a function of the Financial Stress Index (FSI). A significant drawdown is defined as a greater than 1 standard deviation (0.0247) negative return in a month. Therefore the binary choice dependent variable is defined as 1 for a significant drawdown and 0 otherwise in the specification $\operatorname{Pr}(y=1 x, \beta)=\varphi\left(x^{\prime} \beta\right)$, where $\varphi$ is the cumulative distribution function of the standard normal distribution. The results suggest statistically significant effects of greater financial stress in the market increasing the probability of a significant drawdown.

Dependent Variable: NEGRET

Method: ML - Binary Probit (Quadratic hill climbing)

Sample: 2000M01 2008M10

Included observations: 106

Convergence achieved after 5 iterations

Covariance matrix computed using second derivatives

\begin{tabular}{|c|c|c|c|c|}
\hline & Coefficient & Std. Error & z-Statistic & Prob. \\
\hline constant & -1.436662 & 0.196568 & -7.308709 & 0.0000 \\
\hline FSI & 0.446948 & 0.143449 & 3.115719 & 0.0018 \\
\hline McFadden $\mathrm{R}^{2}$ & 0.142782 & \multicolumn{2}{|c|}{ Mean of dependent variable } & 0.113208 \\
\hline S.D. of dep. variable & 0.318352 & \multicolumn{2}{|c|}{ S.E. of regression } & 0.290921 \\
\hline Akaike info criterion & 0.643222 & \multicolumn{2}{|c|}{ Sum of squared residuals } & 8.802070 \\
\hline Schwarz criterion & 0.693476 & \multicolumn{2}{|c|}{ Log likelihood } & -32.09079 \\
\hline Hannan-Quinn criterion & 0.663591 & \multicolumn{2}{|c|}{ Restricted log likelihood } & -37.43595 \\
\hline LR statistic & 10.69033 & \multirow{2}{*}{\multicolumn{2}{|c|}{ Average log likelihood }} & -0.302743 \\
\hline Prob(LR statistic) & 0.001077 & & & \\
\hline Obs. with NEGRET $=0$ & 94 & \multirow{2}{*}{\multicolumn{2}{|c|}{ Total obs. }} & 106 \\
\hline Obs with NEGRET=1 & 12 & & & \\
\hline
\end{tabular}

